desenvolvimento, está também permeando a epidemia da AIDS, como demonstram os dados de tendência mundial apresentados na última conferência internacional de AIDS em Toronto, Canadá ${ }^{2}$. O argumento político-histórico apresentado é consistente e bem fundamentado e com o qual concordo: racializar a epidemia de AIDS na forma demonstrada pode ser, além de pouco fundamentada com os dados disponíveis, uma reversão da forma com que o PN-DST/AIDS tem enfrentado o problema no Brasil, cujo reconhecimento é internacional. É exatamente no conceito do direito de acesso universal e irrestrito aos cuidados em saúde que reside parte de seu sucesso. No entanto, reforço que o argumento epidemiológico da reanálise dos dados apresentados pelos autores é tão falacioso quanto as análises iniciais citadas no texto e apresentadas nos boletins epidemiológicos. Precisamos de dados mais confiáveis, de base populacional, sobre as reais tendências da infecção pelo HIV de forma ampla e consistente. Ademais, uma profunda avaliação do sistema de notificação dos casos de AIDS no que se refere à sua validade e confiabilidade torna-se indispensável. Somente assim, os dados empíricos podem servir de subsídios confiáveis para a elaboração de uma política pública universal, não somente para o tratamento, mas principalmente para a prevenção e promoção da saúde em suas diversas dimensões.

1. Mann J, Tarantola D. AIDS in the world II: global dimensions, social roots, and responses. New York: Oxford University Press; 1996.

2. Joint United Nations Programme on HIV/AIDS. Report on the global AIDS epidemic. Geneva: Joint United Nations Programme on HIV/AIDS; 2006.

\section{Claudia Travassos}

Centro de Informação Científica e Tecnológica Fundação Oswaldo Cruz, Rio de Janeiro, Brasil. claudia@cict.fiocruz.br
Inicialmente, parabenizo os autores do artigo pela oportunidade de colocar em debate a tendência atual no Brasil de associar-se saúde à raça, e as políticas recentes voltadas para viabilizar programas de saúde com foco na "população negra”. Agradeço também o convite para participar como debatedora, por ser este um tema que me mobiliza como cidadã brasileira e como pesquisadora da área da Saúde Pública. Há muito que se sabe que as doenças distribuem-se desigualmente entre os grupos sociais, apesar de as complexas relações entre condição social, adoecimento e morte não serem completamente conhecidas. Uma teoria sobre essas relações considera que, à medida que as doenças aumentam nas populações, a sua distribuição tende a assumir um gradiente social desfavorável aos grupos socialmente menos privilegiados ${ }^{1}$. A AIDS tem sido uma doença particularmente estudada com base nessa teoria. Conforme destacam os autores, no Brasil, como em outros países, a epidemia de AIDS iniciou-se nos grupos socialmente mais privilegiados, mas, à medida que aumentou o número de casos, estes passaram a se concentrar nos grupos sociais menos privilegiados, invertendo, ao longo do tempo, o gradiente social existente no início da epidemia. Vários estudos, como indicado no artigo, mostram que no Brasil a AIDS aumentou entre as mulheres, as pessoas mais pobres, com menos escolaridade, em ocupações menos qualificadas e inseridas no mercado informal de trabalho. Um perfil de distribuição que espelha os vários aspectos de desvantagem social em que vive a grande maioria da população brasileira. Deve ter aumentado também nas pessoas de raça/cor de pele preta e parda, cuja distribuição concentra-se nas posições de maior desvantagem social. Com base nesse quadro, pergunta-se: por que destacar a raça/cor da pele como expressão da pauperização da AIDS no país? Por que deixar de lado a multiplicidade e complexidade dos fatores sociais envolvidos nesse processo? Considero que dar destaque à raça/cor na interpretação das desigualdades sociais em saúde em nosso país não contribui para um melhor entendimento de como são geradas estas desigualdades.

Nos Estados Unidos, raça foi historicamente destacada dentre as demais dimensões de estratificação social. No entanto, o seu emprego, muitas vezes inadequado para analisar relações entre raça (etnia e nacionalidade) e saúde fez com que revistas científicas importantes daquele país, como o New England Journal of Medicine $^{2}$, estabelecessem critérios para a publicação de artigos sobre estas relações. Existe também uma extensa literatura internacional, além de artigos nacionais 3 , que apontam as particularidades da variável raça e cor de pele e fazem recomendações sobre seu emprego na pesquisa em Saúde Pública, de modo a evitar interpretações espúrias. Diferenças conceituais e operacionais implicam que dados de raça/cor sejam publicados com informação aos leitores, visando à orientação destes sobre como os utilizar e os interpretar. Vale lembrar que raça e, particularmente, cor de pele são variáveis bastante dependentes do contexto e devem ser utilizadas e interpretadas a partir deste. Lamentavelmente, a inclusão recente da variável raça/cor nos documentos de saúde no Brasil não se orientou por essas recomendações. Essas recomendações estão voltadas para 
produzir informação de melhor validade a fim de gerar conhecimento necessário para orientar políticas de redução das iniqüidades em saúde. Compartilho, portanto, da crítica dos autores sobre o destaque dado a raça/cor na AIDS, tal como apresentado no boletim epidemiológico do PN-DST/AIDS de 2005. Surpreende que afirmações sobre a relação raça/cor e AIDS sejam publicadas em documento oficial do Ministério da Saúde sem considerar as particularidades da informação sobre raça/cor e as limitações dos dados disponíveis. Como exemplos, empregaram-se dados com altos percentuais de casos ignorados, variando entre $41,5 \%$ e $88 \%$. Os dados mais recentes são oriundos de um novo banco, já que os dados do SINAN passaram a incorporar casos novos provenientes de outros bancos de dados: SISCEL (Sistema de Controle de Exames Laboratoriais) e SICLOM (Sistema de Controle Logístico de Medicamentos). A qualidade dos dados do SINAN, após a integração, ainda é pouco conhecida e tem sido questionada.

Por fim, é importante se reconhecer que a existência de discriminação é um fator importante na geração das desigualdades sociais em saúde, mas focar isoladamente a discriminação racial é abordar apenas parte do problema, senão distorcê-lo. Com relação à discriminação social que ocorre nos serviços de saúde, talvez tenhamos no PN-DST/AIDS uma experiência de sucesso. A diminuição nas desigualdades sociais na mortalidade por AIDS em São Paulo ${ }^{4}$ é um indicativo desse sucesso. O compromisso da sociedade brasileira com a universalidade do acesso ao tratamento da AIDS reconhece os direitos de todas as pessoas com AIDS, uma doença marcada pela estigmatização e discriminação, e representa uma postura contra qualquer tipo de discriminação.

1. Smith GD, Infection, medical care and inequalities. Int J Epidemiol 2005; 32:507-8.

2. Schwartz RS. Racial profiling in medical research. N Engl J Med 2001; 344:1392-3.

3. Travassos C, Williams D. The concept and measurement of race and their relationship to public health: a review focused on Brazil and the United States. Cad Saúde Pública 2004; 20:660-78.

4. Antunes JLF, Waldman EA, Borell C. Is it possible to reduce AIDS deaths without reinforcing socioeconomic inequalities in health? Int J Epidemiol 2005; 34:586-92.
José Ricardo de C. M. Ayres

Faculdade de Medicina, Universidade de São Paulo, São Paulo, Brasil. jrcayres@usp.br
Raça como conceito emancipador e vulnerabilidade como norte para políticas de eqüidade em saúde

Muito oportuno e instigante o artigo de Fry et al. Por duas razões relacionadas. Primeiro por abordar de forma franca as complexas e polêmicas relações entre raça e saúde. Segundo, por recolocar a discussão, ainda longe de ser esgotada, acerca do uso de análises epidemiológicas como fundamento de políticas de saúde.

Comecemos pela questão central: o aspecto raça. É de fato uma questão difícil. Ainda que poucos de nós discordemos do ideal de busca da eqüidade na saúde, e que saibamos que no Brasil, como de resto em uma diversidade de países do mundo, a construção do ideal da eqüidade não pode ignorar as diferentes necessidades relacionadas a aspectos étnico-raciais, não há consenso quanto ao modo concreto de alcançar este ideal. A primeira dificuldade vem do próprio conceito de raça.

Raça já foi um conceito amplamente explorado por ideologias, filosofias (e até tentativas de ciência) instruídas pela noção de eugenia, no início do século XX. Antes, porém, que os próprios progressos científicos da genética esvaziassem seu valor cognitivo, reações de caráter moral cercearam o uso ampliado do conceito, seja pela crítica ao seu sentido naturalizador de questões determinadas socioculturalmente, seja pela recusa de práticas estigmatizantes e discriminatórias que resultaram de seu uso. Ocorre que, por essas voltas que a história dá, a idéia de raça acabou por assumir no movimento social, em escala global, especialmente entre populações negras, um sentido diametralmente oposto àquele que predominou nas abordagens eugenistas do início do século passado: em vez de característica biológica determinada por herança genética, a raça passou a constituir um traço identitário voluntariamente assumido e ativamente construído; no lugar de um conceito opressor e negativamente discriminatório, um conceito voltado para a emancipação e para a afirmação positiva de resistência à iniqüidade. O que sustenta a nova "conceitualidade" da raça é, de um lado, a crescente produção de evidências de que, entre os fundamentos da distribuição desigual de poder, riqueza, bemestar e desenvolvimento humano em nossas sociedades, a distinção racial vem ocupando historicamente um lugar destacado. De outro lado, essa nova conceitualidade expressa e constrói a aposta em que a organização de respostas sociais em torno à identidade racial poderá levar à 